\title{
MODELOS DE MACHINE LEARNING PARA PREDIÇÃO DO SUCESSO DE STARTUPS
}

\author{
MACHINE LEARNING MODELS FOR PREDICTING SUCCESS OF STARTUPS
}

\author{
Fabiano Rodrigues \\ Doutor em Administração, FEA-USP \\ ESPM / PPGA \\ frodrigues@espm.br
}

Francisco Aparecido Rodrigues

Doutor em Física, Instituto de Física de São Carlos (USP) Instituto de Ciências Matemáticas e de Computação, Universidade de São Paulo franscisco@icmc.usp.br

Thelma Valéria Rocha Rodrigues

Doutora em Administração, FEA-USP

ESPM / PPGA

tvrocha@espm.br

\begin{abstract}
Resumo
Este estudo analisa resultados obtidos com modelos de machine learning para predição do sucesso de startups. Como proxy de sucesso considera-se a perspectiva do investidor, na qual a aquisição da startup ou realização de IPO (Initial Public Offering) são formas de recuperação do investimento. A revisão da literatura aborda startups e veículos de financiamento, estudos anteriores sobre predição do sucesso de startups via modelos de machine learning, e trade-offs entre técnicas de machine learning. Na parte empírica, foi realizada uma pesquisa quantitativa baseada em dados secundários oriundos da plataforma americana Crunchbase, com startups de 171 países. O design de pesquisa estabeleceu como filtro startups fundadas entre junho/2010 e junho/2015, e uma janela de predição entre junho/2015 e junho/2020 para prever o sucesso das startups. A amostra utilizada, após etapa de pré-processamento dos dados, foi de 18.571 startups. Foram utilizados seis modelos de classificação binária para a predição: Regressão Logística, Decision Tree Random Forest, Extreme Gradiente Boosting, Support Vector Machine e Rede Neural. Ao final, os modelos Random Forest e Extreme Gradient Boosting apresentaram os melhores desempenhos na tarefa de classificação. Este artigo, envolvendo machine learning e startups, contribui para áreas de pesquisa híbridas ao mesclar os campos da Administração e Ciência de Dados. Além disso, contribui para investidores com uma ferramenta de mapeamento inicial de startups na busca de targets com maior probabilidade de sucesso.
\end{abstract}

Palavras-chave: Predição do sucesso de startups. Machine learning. Investimento em startups. Plataforma crunchbase.

Abstract

This study analyzes results from machine learning models to predict the success of startups. As a proxy for success, we considered the investor's perspective, according to which startup buyout or IPO (Initial Public Offering) are ways to recover the investment. The literature review addresses startups and funding mechanisms, previous studies on prediction of startup success via machine learning models, and trade-offs between machine learning techniques. The empirical study comprised a quantitative research based on secondary data from the American Crunchbase platform, with startups from 171 countries. The research design used as filter startups founded between June/2010 and June/2015, as well as a prediction window from June/2015 to June/2020 to predict startup success. The final sample, after the data preprocessing stage, comprised 18,571 startups. Six binary classification models were used for success prediction: Logistic Regression, Decision Tree, Random Forest, Extreme Gradient Boosting, Support Vector Machine, and Neural Networks. In the end, the Random Forest and Extreme Gradient Boosting models had the best performance in the classification task. This article involving machine learning and startups contributes to research in hybrid fields by combining perspectives from Business and Data Science. Additionally, it contributes to investors with a tool for initial mapping of startups in search of targets with greater probability of success.

Keywords: Startup success prediction. Machine learning. Investment in startups. Crunchbase platform.

Cite como

American Psychological Association (APA)

Rodrigues, F., Rodrigues, F. A., \& Rodrigues, T. V. R. (2021, maio/ago.). Modelos de machine learning para predição do sucesso de startups. Revista de Gestão e Projetos (GeP), 12(2), 28-55. https://doi.org/10.5585/gep.v12i2.18942. 


\section{Introdução}

Nos últimos anos, o número global de unicórnios (startups com valor de mercado acima de um bilhão de dólares) vem aumentando. Em dezembro de 2020, 506 startups foram enquadradas nesta categoria, com valuation acumulado de aproximadamente US\$ 1.6 trilhões de dólares (CB Insights, 2020). Por outro lado, apenas metade das startups conseguem sobreviver mais de cinco anos (National, 2020).

Startups, por definição, são organizações temporárias usadas para procurar um modelo de negócios repetível e com alta escalabilidade (Blank, 2013). Essa busca por modelos de sucesso é bastante volátil, tanto para os empreendedores como para os investidores. Afinal, startups são instituições humanas desenhadas para entregar um novo produto ou serviço sob condições de extrema incerteza (Ries, 2012). As incertezas são múltiplas, de natureza tecnológica, financeira, mercadológica, macroeconômica, de encaixe entre a oferta criada e a necessidade dos consumidores, de condições e forma de gerenciamento, entre outras.

Fundos de Venture Capital (VC) realizam investimentos com o intuito de auferirem retornos advindos do desinvestimento (exit), ou seja, quando a startup investida é adquirida por outra organização ou abre seu capital por meio de um IPO - Initial Public Offering. Empreendedores, além do propósito que movimenta suas organizações, também buscam investimentos para auxiliá-los nas diversas fases do seu empreendimento.

Diante desse cenário de alto risco e potencial alto retorno, prever as startups com maiores chances de sucesso pode ajudar o ecossistema empreendedor, reunindo investidores a iniciativas com maior potencial de rentabilização e oferecendo aos empreendedores uma bússola para checar a probabilidade de terem sucesso no desenvolvimento de suas iniciativas.

O sucesso de uma startup pode ser definido de muitas formas: pela capacidade de atração de novos investimentos (funding rounds), pela velocidade exponencial de crescimento das vendas, pela participação em processos de $M \& A$ (Mergers and Acquisitions), e pela abertura de capital via $I P O$.

Este estudo assume a perspectiva do investidor, usando exit como proxy para o sucesso. Exit é o termo usado para a saída do investidor; isso ocorre quando a startup é adquirida por outra empresa (processo de $M \& A$ ) ou realiza uma oferta pública de suas ações (processo de IPO). Nos dois casos, os investidores podem vender suas participações para auferir ganhos nas transações. Dessa forma, o objetivo deste estudo consiste em analisar os resultados de modelos de machine learning para a predição do sucesso de startups. Os modelos preditivos são de classificação binária: sucesso - ou não - das startups.

A literatura acadêmica com foco em machine learning para predição do sucesso de 
startups já conta com frentes de pesquisa nessa direção, que contribuíram para o presente estudo (Liang \& Daphne Yuan, 2013; Shan, Cao \& Lin, 2014; Bento, 2017; Pan, Gao \& Luo, 2018; Gastaud, Carniel \& Dalle, 2019; Arroyo et al., 2019). Na última década, vários modelos foram testados para essa tarefa, incluindo Naive Bayes, Decision Trees, Random Forest, Supported Vector Machine, entre outros. Os autores citados concentram-se majoritariamente no campo da computação e ciência de dados. Este estudo inspira-se no design de janelas temporais proposto por Arroyo et al. (2019), incluindo apenas startups com data de fundação recente, entre junho de 2010 e junho de 2015 , para prever seu sucesso entre junho de 2015 e junho de 2020.

Como contribuição acadêmica, realizaram-se algumas mudanças no design da pesquisa desenvolvida por Arroyo et al. (2019) e na estratégia de tratamento dos dados, tais como: tempo das janelas de inclusão e predição; adição de startups com período inferior a dois anos para captação na primeira rodada de financiamento; adoção de estratégia conservadora para tratamento de dados faltantes; inclusão de redes neurais do tipo multi layer perceptron ao conjunto de modelos avaliados para a tarefa de classificar e inclusão de atributos preditivos aderentes ao contexto empreendedor. Adicionalmente, devido ao background dos autores da pesquisa, este estudo contribui com a aproximação dos campos da Ciência de Dados e da Administração.
Para o ecossistema empreendedor, este estudo propõe filtrar startups que tenham maior probabilidade de sucesso para os investidores. Em um cenário extremamente competitivo e incerto, onde mais de $90 \%$ das startups falham (Profitfromtech, 2020), o estudo auxilia na identificação das mais promissoras. Também destaca a relevância de modelos de machine learning no processo de varredura inicial de oportunidades de investimento, agregando uma camada para filtrar as startups com maior potencial de sucesso.

Como estrutura, este estudo inclui uma revisão teórica sobre o tema, o desenvolvimento do design da pesquisa, tratamento e limpeza dos registros de startups oriundos da plataforma Crunchbase (2020), uma análise exploratória, e predição do sucesso de startups a partir de modelos de classificação desenvolvidos em linguagem de programação Python.

\section{Revisão teórica}

Nesta seção são abordados o conceito de startups, veículos para financiamento de suas atividades, estudos anteriores sobre predição do sucesso de startups e modelos de machine learning.

\subsection{Startups e veículos de financiamento}

Startups, por definição, são organizações temporárias usadas para procurar um modelo de negócios repetível e com alta escalabilidade (Blank, 2013). São ideias que se multiplicaram nas últimas décadas e foram 
postas à prova em ambientes de alta incerteza, mas com potencial de atração de demanda.

$\mathrm{O}$ surgimento de bases de dados sobre startups, como a Crunchbase, facilita o acesso a grande quantidade e variedade de dados estruturados, com potenciais usos para múltiplos stakeholders: fundadores em busca de financiamento, investidores à procura de startups, pessoas em busca de ideias para novos empreendimentos, e pesquisadores acadêmicos que se interessam pela dinâmica e pelo ecossistema das startups (Crunchbase, 2020).

Crunchbase é uma plataforma mundial criada em 2007, com sede nos Estados Unidos, para profissionais que buscam dados sobre empresas inovadoras. Dalle, den Besten e Menon (2017) identificaram mais de 90 artigos acadêmicos usando o Crunchbase como fonte de dados para estudos em variados campos, como gestão e economia.

A fotografia da base de dados Crunchbase, no dia 29 junho de 2020, apresentava 1.064.929 startups e informações sobre 906.248 fundadores (extração realizada pelos autores, com a devida autorização da equipe Crunchbase para fins acadêmicos). A base possui um histórico com mais de $325 \mathrm{mil}$ rodadas de financiamento (funding rounds), em todas as etapas do ciclo de vida de uma startup: early-, growth- e mature stage (nascimento, crescimento e maturidade).

Para exemplificar essa lógica de funding no cenário brasileiro, Gereto (2019) analisou o ciclo de investimento e desinvestimento de 436 startups brasileiras registradas na base de dados Crunchbase. Nesse estudo, visualizou uma média de 1,7 rodadas de investimento do tipo seed; 2,2 rodadas em early stage; e 3,6 rodadas em later stage, com faixas crescentes captadas ao longo do ciclo de vida da startup: US\$ $100.000,00$ a US\$ $1.000 .000,00$ (seed); US\$1.000.000,00 a US\$10.000.000,00 (early stage); e US\$ $10.000 .000,00$ a US\$ 100.000.000,00 (later stage). A Tabela 1 apresenta diferentes tipos de financiamento de startups 
Tabela 1 - Tipos de funding no ciclo de vida das startups

\begin{tabular}{|l|l|l|}
\hline \multicolumn{1}{|c|}{ Descrição } & \multicolumn{1}{|c|}{ Fontes (\$) mais comuns } \\
\hline Pre-Seed & $\begin{array}{l}\text { Estágios embrionários da startup (início do seu ciclo } \\
\text { de vida) }\end{array}$ & $\begin{array}{l}\text { Investidores anjos, amigos, familiares e } \\
\text { capital próprio }\end{array}$ \\
\hline $\begin{array}{l}\text { Seed- } \\
\text { Round }\end{array}$ & $\begin{array}{l}\text { Startup começa a ganhar tração, mas ainda está no } \\
\text { início de sua operação. Alguns investidores mais } \\
\text { qualificados começam a sondar as startups para } \\
\text { ampliar e diversificar seu portfólio de investimentos. }\end{array}$ & $\begin{array}{l}\text { Investidores anjos, incubadoras, aceleradoras } \\
\text { alguns fundos de venture capital (VC) } \\
\text { começam sondagens. }\end{array}$ \\
\hline \multirow{5}{*}{$\begin{array}{l}\text { Startup já apresenta alguma prova de conceito / } \\
\text { modelo. Torna-se possível analisar resultados reais } \\
\text { obtidos a partir de rodadas de funding anteriores. }\end{array}$} & $\begin{array}{l}\text { Investidores anjos com maior capacidade, } \\
\text { venture capital, Family offices e alguns } \\
\text { fundos de private equity. } \\
\text { que a startup atinja novos patamares. }\end{array}$ \\
\hline Series B $B$ & $\begin{array}{l}\text { Neste ponto, as expectativas são mais ousadas, como } \\
\text { por exemplo: forte expansão territorial, ampliação de } \\
\text { canais de vendas e ganho de escala em ritmo mais } \\
\text { acelerado. }\end{array}$ & $\begin{array}{l}\text { Investidores parecidos com as rodadas } \\
\text { anteriores, com maior apetite pelo potencial } \\
\text { de crescimento da startup. Nesta fase, } \\
\text { investidores anteriores podem auxiliar na } \\
\text { captação de novos interessados. }\end{array}$ \\
\hline $\begin{array}{l}\text { Series } C \\
\text { e mais }\end{array}$ & $\begin{array}{l}\text { Este milestone indica um aumento na probabilidade de } \\
\text { sucesso da startup. Neste ponto, provavelmente, o } \\
\text { negócio já esteja validado, operando em alta escala e } \\
\text { apresentando maior valuation. Investidores já } \\
\text { começam a pensar em estratégias de saída. }\end{array}$ & $\begin{array}{l}\text { As exigências feitas por novos investidores } \\
\text { nesta fase costumam ser maiores, com } \\
\text { crescente expectativa sobre controle, dados e } \\
\text { due dilligence, por exemplo. }\end{array}$ \\
\hline
\end{tabular}

Fonte: Adaptado de Losada (2020, p. 124).

No começo do ciclo de vida da startup, a competição por recursos é bastante expressiva, tanto pelo volume de ofertas como pela busca de diversificação de ativos por parte dos investidores.

A passagem pelas rodadas de financiamento é uma sinalização de que a startup está trilhando um caminho de potencial sucesso para os investidores. A profissionalização do dinheiro investido aumenta, até mesmo com a indicação de executivos de venture capital para posiçõeschave na gestão da startup (Cremades, 2016).

Ao longo do ciclo de vida das startups, os investidores vão gradativamente aumentando suas preocupações quanto às estratégias de saída (exit). As estratégias de saída mais comuns, com potencial geração de ganhos, são um $I P O$ ou uma venda competitiva. Em um cenário negativo, caso de fracasso da startup, os investimentos realizados são perdidos (Losada, 2020).

\subsection{Predição do sucesso de startups: estudos anteriores com machine learning}

Nos últimos anos, muitos estudos sobre startups têm usado técnicas de machine learning como apoio à geração de insights e conhecimentos. Pesquisas sobre ecossistemas empreendedores (Nylund \& Cohen, 2017; Kemeny, Nathan \& Almeer, 2017; Kosterich \& Weber, 2018; Basole, Park \& Chao, 2019), sucesso de startups, mercados específicos como fintechs (Hsieh \& Li, 2017), seleção de oportunidades para investimento e capital de risco são alguns exemplos. A Tabela 2 sintetiza alguns estudos relacionados à predição do 
sucesso de startups com técnicas de machine

learning, a partir de dados da plataforma

Crunchbase.

Tabela 2 - Predição do sucesso de startups: síntese de estudos relacionados

\begin{tabular}{|c|c|c|c|c|}
\hline Referência & Objetivo & Amostra & $\begin{array}{c}\text { Variável de } \\
\text { Interesse }\end{array}$ & $\begin{array}{l}\text { Técnicas de } \\
\text { Machine } \\
\text { Learning }\end{array}$ \\
\hline $\begin{array}{l}\text { Liang e } \\
\text { Daphne Yuan } \\
\text { (2013) }\end{array}$ & $\begin{array}{l}\text { Investigar o papel das relações } \\
\text { sociais entre investidores e empresas } \\
\text { para a predição do comportamento de } \\
\text { investimento. }\end{array}$ & $\begin{array}{l}11.916 \text { startups, } \\
12.127 \text { pessoas, } \\
1.122 \text { organizações } \\
\text { financeiras }\end{array}$ & $\begin{array}{l}\text { Ocorrência de } \\
\text { investimento }\end{array}$ & $\begin{array}{l}\text { SVM, Árvore } \\
\text { de Decisão e } \\
\text { Naive Bayes }\end{array}$ \\
\hline $\begin{array}{l}\text { Shan, Cao e } \\
\text { Lin (2014) }\end{array}$ & $\begin{array}{l}\text { Prever se um investidor investirá em } \\
\text { uma startup específica com base em } \\
\text { sinais textuais, topológicos e } \\
\text { específicos do domínio }\end{array}$ & $\begin{array}{l}214.290 \text { startups, } \\
286.659 \text { pessoas, } \\
31.942 \\
\text { investimentos }\end{array}$ & $\begin{array}{l}\text { Investidor } \\
\text { efetiva } \\
\text { investimento } \\
\text { em startup }\end{array}$ & $\begin{array}{c}\text { Regressão } \\
\text { Logística }\end{array}$ \\
\hline Bento (2017) & $\begin{array}{l}\text { Desenvolver um modelo preditivo } \\
\text { para classificar uma startup como } \\
\text { bem-sucedida, ou não (classificação } \\
\text { binária) }\end{array}$ & $\begin{array}{l}86588 \text { startups } \\
\text { (estados } \\
\text { americanos) }\end{array}$ & $\begin{array}{l}\text { IPO ou } \\
\text { Aquisição da } \\
\text { startup }\end{array}$ & $\begin{array}{c}\text { Floresta } \\
\text { Aleatória, } \\
S V M \text { e } \\
\text { Regressão } \\
\text { Logística }\end{array}$ \\
\hline $\begin{array}{l}\text { Pan, Gao e } \\
\text { Luo (2018) }\end{array}$ & $\begin{array}{l}\text { Predizer o sucesso de startups, } \\
\text { definido como um evento que dá uma } \\
\text { grande quantia aos fundadores e } \\
\text { investidores }\end{array}$ & +60.000 startups & $\begin{array}{l}\text { Processo de } \\
M \& A \text { ou } I P O\end{array}$ & $\begin{array}{l}\text { KNN, Floresta } \\
\text { Aleatória e } \\
\text { Regressão } \\
\text { Logística }\end{array}$ \\
\hline $\begin{array}{l}\text { Arroyo et al. } \\
(2019)\end{array}$ & $\begin{array}{l}\text { Desenvolvimento e avaliação de uma } \\
\text { abordagem orientada por dados que } \\
\text { usa machine learning para ajudar os } \\
\text { investidores de } V C \text { a explorar e } \\
\text { selecionar as melhores empresas para } \\
\text { apoiar. }\end{array}$ & $\begin{array}{l}120.507 \text { startups, } \\
34.180 \text { funding } \\
\text { rounds }\end{array}$ & $\begin{array}{l}\text { Aquisição, } \\
\text { rodada de } \\
\text { financiamento, } \\
I P O, \\
\text { fechamento ou } \\
\text { nenhum } \\
\text { evento }\end{array}$ & $\begin{array}{l}\text { Gradient Tree } \\
\text { Boosting, } \\
\text { Árvore de } \\
\text { Decisão, } \\
\text { Floresta } \\
\text { Aleatória e } \\
\text { SVM. }\end{array}$ \\
\hline $\begin{array}{l}\text { Gastaud, } \\
\text { Carniel e } \\
\text { Dalle (2019) }\end{array}$ & $\begin{array}{l}\text { Predizer o sucesso de startups na } \\
\text { arrecadação de investimentos em } \\
\text { diferentes estágios (early-, growth- e } \\
\text { late stage) }\end{array}$ & 65.957 startups & $\begin{array}{l}\text { Obtenção de } \\
\text { funding em } \\
\text { diferentes } \\
\text { estágios (seed, } \\
\text { series A e B) }\end{array}$ & $\begin{array}{c}\text { Floresta } \\
\text { Aleatória, } \\
\text { Graph Neural } \\
\text { Networks }\end{array}$ \\
\hline
\end{tabular}

Fonte: Elaborado pelos autores (2021).

representam estratégias de saída (exit) para que

A variável de interesse é investidores tentem auferir ganhos.

operacionalizada de diversas formas. Dentre os estudos apresentados na Tabela 2, os eventos $I P O$ e/ou aquisição de uma startup destacam-se Outros estudos estabelecem rodadas de como variáveis para o sucesso (Bento, 2017; Pan, Gao \& Luo, 2018; Arroyo et al., 2019). Um processo de $M \& A$, bem como um IPO, 
startup, fechamento, IPO, rodada de financiamento, e nenhum evento.

Sobre as técnicas de machine learning usadas, destacam-se as de aprendizado supervisionado com classificação binária. As técnicas mais utilizadas foram Regressão Logística, Árvore de Decisão, Floresta Aleatória e SVM. Redes Bayesianas, KNN e Naive Bayes foram menos presentes (Liang \& Daphne Yuan, 2013; Pan, Gao \& Luo, 2018). Recentemente, um estudo usou Gradient Tree Boosting no processo de predição do sucesso de startups (Arroyo et al., 2019) e outro utilizou Graph Neural Networks (Gastaud, Carniel \& Dalle, 2019); ambos os estudos obtiveram resultados e modelagens promissoras.

\subsection{Modelos de machine learning}

Machine learning (ML), ou aprendizado de máquina, é um dos principais ramos da Inteligência Artificial. Os impactos dos modelos de machine learning são cada vez mais presentes no dia a dia de pessoas e organizações, seja em aplicações para reconhecimento de voz, detecção de fraudes bancárias, sistemas de recomendação de filmes e músicas em plataformas de streaming, sistemas de busca de dados, entre outros. Nos bastidores dessas aplicações, os algoritmos de $M L$ buscam aprender com grandes volumes de dados, estruturados ou não, identificando padrões para classificação ou regressão.

Do ponto de vista computacional, machine learning caracteriza-se como "o estudo de algoritmos de computador que melhoram automaticamente através da experiência" (Ertel, 2017, p. 178). Similarmente, Facelli et al. (2019, p. 3) argumentam que, em $M L$ : “... computadores são programados para aprender com a experiência passada. Para tal, empregam um princípio de inferência denominado indução, no qual se obtém conclusões genéricas a partir de um conjunto particular de exemplos". Assim, modelos de $M L$ aprendem a induzir hipóteses ou funções que consigam resolver o problema (de regressão ou classificação) a partir do conjunto de dados de treinamento.

Figura 1 - Processo simplificado de aprendizagem

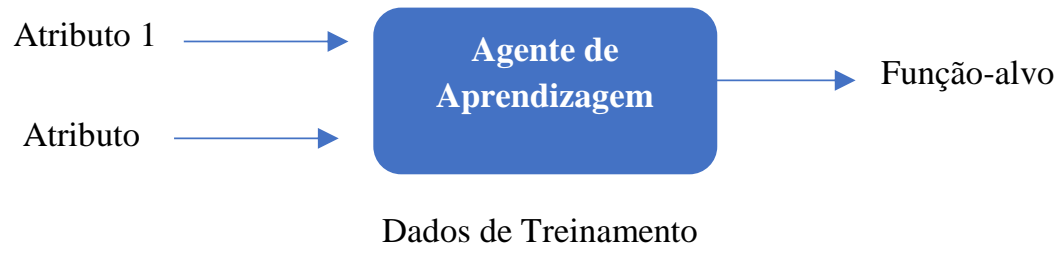

Fonte: Adaptado de Ertel (2017, p. 178).

Um agente de aprendizagem é bemnovos e desconhecidos ao longo do tempo (após muitos exemplos de treinamento)" (Ertel,

sucedido se "melhorar seu desempenho (medido por um critério adequado) em dados 
2017, p. 178). As tarefas de aprendizagem podem ser divididas em aprendizado supervisionado e não supervisionado.

$\mathrm{Na}$ aprendizagem supervisionada, foco deste estudo, tenta-se prever uma variável-alvo a partir de um conjunto de atributos, por meio de classificação ou regressão. $\mathrm{O}$ termo supervisionado refere-se ao conhecimento inicial do estado da variável dependente do modelo, para cada vetor de atributos dos exemplos contidos no conjunto dos dados de treinamento. Já na aprendizagem não supervisionada, a predição cede espaço para a descrição, seja na forma de agrupamento, associação ou sumarização. Neste caso, não existe um atributo-alvo a priori, buscam-se padrões entre atributos ou objetos contidos no conjunto de dados.

Skiena (2017) argumenta que, dificilmente, um algoritmo de $M L$ seja superior a todos, pela diversidade de domínios, contextos do problema de decisão, e da própria característica dos dados.

A Tabela 3 mostra uma avaliação subjetiva, em uma escala de 1 (pior) a 10 (melhor), de algumas técnicas de $M L$ em cinco dimensões: poder, facilidade de interpretação, facilidade de uso, velocidade de treinamento e velocidade de predição.

Tabela 3 - Avaliação subjetiva das técnicas de $M L$

\begin{tabular}{|l|c|c|c|c|c|}
\hline \multicolumn{1}{|c|}{ Técnica } & Poder & $\begin{array}{c}\text { Facilidade de } \\
\text { Interpretação }\end{array}$ & $\begin{array}{c}\text { Facilidade } \\
\text { de Uso }\end{array}$ & $\begin{array}{c}\text { Velocidade de } \\
\text { Treinamento }\end{array}$ & $\begin{array}{c}\text { Velocidade } \\
\text { de Predição }\end{array}$ \\
\hline Regressão linear & 5 & 9 & 9 & 9 & 9 \\
\hline Vizinho mais próximo $(K N N)$ & 5 & 9 & 8 & 10 & 2 \\
\hline Naive Bayes & 4 & 8 & 7 & 9 & 8 \\
\hline Árvore de decisão & 8 & 8 & 7 & 7 & 9 \\
\hline Máquinas de vetores de suporte & 8 & 6 & 6 & 7 & 7 \\
\hline Boosting & 9 & 6 & 6 & 6 & 6 \\
\hline Graphical Models & 9 & 8 & 3 & 4 & 4 \\
\hline Deep Learning & 10 & 3 & 4 & 3 & 7 \\
\hline
\end{tabular}

Fonte: Adaptado de Skiena (2017, p. 353).

Há um trade-off natural entre as dimensões expostas na Tabela 3. Algumas técnicas propiciam maior facilidade para a interpretação dos resultados (Árvore de Decisão, por exemplo). Já outras, como Deep Learning, possuem alto poder de predição e menor facilidade de interpretação.

A Tabela 4 apresenta as técnicas usadas e os principais resultados dos 6 estudos (ver Tabela 2) que usaram como fonte de dados a base Crunchbase. A técnica mais utilizada foi a Floresta Aleatória (Random Forest), seguida das técnicas de Regressão Logística e $S V M$. As três técnicas menos utilizadas, empregadas em pesquisas mais recentes, foram KNN, Gradient Tree Boosting e Graph Neural Networks. 
Tabela 4 - Técnicas de machine learning versus artigos com a base Crunchbase

\begin{tabular}{|c|c|c|c|c|c|c|}
\hline $\begin{array}{l}\text { TÉCNICA VS } \\
\text { ARTIGO VS } \\
\text { RESULTADO }\end{array}$ & $\begin{array}{l}\text { Liang e } \\
\text { Daphne } \\
\text { Yuan } \\
(\mathbf{2 0 1 3})\end{array}$ & $\begin{array}{l}\text { Shan, Cao } \\
\text { e Lin } \\
(2014)\end{array}$ & $\begin{array}{l}\text { Bento } \\
(2017)\end{array}$ & $\begin{array}{l}\text { Pan, Gao e } \\
\text { Luo (2018) }\end{array}$ & $\begin{array}{l}\text { Arroyo et al. } \\
\qquad(2019)\end{array}$ & $\begin{array}{c}\text { Gastaud, } \\
\text { Carniel e } \\
\text { Dalle (2019) }\end{array}$ \\
\hline $\begin{array}{l}\text { Regressão } \\
\text { logística }\end{array}$ & & $\begin{array}{c}\text { Precisão } \\
(\mathbf{0 . 8 6 4 )}\end{array}$ & $\begin{array}{c}\text { Acurácia } \\
(0.928)\end{array}$ & $\begin{array}{l}\text { Acurácia } \\
(72.54 \%)\end{array}$ & & \\
\hline Naive Bayes & $\begin{array}{c}\text { TPR } \\
(54.80 \%)\end{array}$ & & & & & \\
\hline $\begin{array}{l}\text { Árvore de } \\
\text { decisão }\end{array}$ & $\begin{array}{c}\text { TPR } \\
(87.53 \%)\end{array}$ & & & & $\begin{array}{c}\text { Precisão } \\
(0.09, \text { aquisição }) \\
(0.04, I P O)\end{array}$ & \\
\hline $\begin{array}{l}\text { Floresta } \\
\text { aleatória }\end{array}$ & & & $\begin{array}{c}\text { Acurácia } \\
(\mathbf{0 . 9 3 1 )}\end{array}$ & $\begin{array}{l}\text { Acurácia } \\
(\mathbf{8 4 . 5 3 \% )}\end{array}$ & $\begin{array}{c}\text { Precisão } \\
(\mathbf{0 . 3 3}, \text { aquisição }) \\
(\mathbf{0 . 4 4}, I P O) \\
\end{array}$ & $\begin{array}{c}\text { Precisão } \\
(0.63)\end{array}$ \\
\hline$K N N$ & & & & $\begin{array}{l}\text { Acurácia } \\
(73.33 \%)\end{array}$ & & \\
\hline$S V M$ & $\begin{array}{c}\text { TPR } \\
(\mathbf{8 9 . 5 8 \% )}\end{array}$ & & $\begin{array}{c}\text { Acurácia } \\
(0.928)\end{array}$ & & $\begin{array}{c}\text { Precisão } \\
(0.00, \text { aquisição) } \\
(0.00, I P O) \\
\end{array}$ & \\
\hline $\begin{array}{l}\text { Gradient tree } \\
\text { boosting }\end{array}$ & & & & & $\begin{array}{c}\text { Precisão } \\
(0.17, \text { aquisição }) \\
(0.07, I P O) \\
\end{array}$ & \\
\hline $\begin{array}{l}\text { Graph neural } \\
\text { network }\end{array}$ & & & & & & $\begin{array}{c}\text { Precisão } \\
(\mathbf{0 . 6 5})\end{array}$ \\
\hline
\end{tabular}

Fonte: Elaborado pelos autores (2021).

Em termos das medidas de avaliação de classificadores, Kubat (2017) aponta que precisão consiste na probabilidade de $\mathrm{o}$ classificador estar correto quando classifica um exemplo como positivo, enquanto um alto recall significa a porcentagem de exemplos positivos classificados como positivos. A acurácia é o indicador mais simples, consiste na razão entre o número de predições corretas pelo total de predições. A pontuação $\mathrm{F} 1$ é a média harmônica entre precisão e recall. Já a medida GMean, que é bastante usada no caso de datasets desbalanceados, basicamente consiste na média geométrica entre a sensibilidade (recall) e a especificidade (porcentagem de exemplos negativos classificados como negativos) do modelo.

Arroyo et. al (2019) obtiveram menor precisão em seus modelos em comparação com
Shan, Cao e Lin (2014). As melhores precisões foram obtidas com o modelo de Floresta Aleatória, com 0,33 para startups adquiridas e 0,44 para as que realizaram processo de $I P O$. Importante destacar que esse estudo, após reinterpretação e nova operacionalização do conceito de sucesso das startups, atingiu precisão superior a $60 \%$. Em resumo, os autores classificaram como bem-sucedidas startups que foram adquiridas, que realizaram IPO, ou que continuavam recebendo funding (o fracasso foi designado apenas para startups fechadas ou sem eventos na janela de simulação do estudo).

$\mathrm{O}$ primeiro estudo usou janelas temporais para avaliação dos modelos. Nesse caso, estabeleceram-se duas janelas: 1) de aquecimento, com duração de 4 anos, entre ago/2011 e ago/2015 (contendo startups não adquiridas, sem $I P O$, operantes e com rodada de 
financiamento inferior à série C); e 2) de simulação, entre ago/2015 e ago/2018, para captura do primeiro evento entre as seguintes opções: aquisição, fechamento, $I P O$, rodada de financiamento, e nenhum evento para uma startup da janela de aquecimento. $\mathrm{O}$ segundo estudo teve outro design, incorporando sinais textuais, topológicos e específicos do domínio, tanto do investidor quanto da startup.

Bento (2017), criticado por Arroyo et al. (2019) pela inclusão de startups fundadas desde 1985 (data anterior à criação da plataforma Crunchbase), apresentou alta acurácia em seus modelos. O autor trabalhou com o maior número de atributos (158), usando apenas dados de alguns estados americanos de forma agregada. Além disso, o uso da acurácia como métrica de avaliação de desempenho para datasets desbalanceados deve ser vista com cautela, pois verifica a proporção de casos corretamente classificados, sejam verdadeiros positivos ou verdadeiros negativos. Como, muitas vezes, o interesse analítico recai na classe minoritária, a acurácia pode ser enviesada pelo desempenho da classe majoritária.

Nota-se que diferentes designs de pesquisa (janelas de simulação, filtros para eleger startups válidas para o estudo), quantidade e tipos de atributos usados, as etapas de pré-processamento e transformação dos dados, além das métricas de avaliação de desempenho dos modelos, podem interferir na qualidade e na interpretação dos resultados.

A próxima seção tratará da metodologia do presente estudo, seus materiais, métodos, pré-processamento e tratamento das variáveis, escolha dos atributos, design e operacionalização da pesquisa.

\section{Metodologia}

O percurso metodológico contempla a modelagem do design da pesquisa, a partir das tabelas da base de dados Crunchbase e do design macro do estudo, bem como o tratamento da base de dados (pré-processamento, limpeza, transformação e criação de novos atributos preditivos), culminando na apresentação e discussão dos resultados advindos de seis modelos de machine learning desenvolvidos em linguagem de programação Python. A Figura 2 apresenta os principais passos da pesquisa quantitativa baseada na análise de dados secundários.

Figura 2 - Percurso metodológico

\begin{tabular}{|c|c|c|}
\hline $\begin{array}{l}\begin{array}{c}\text { Modelagem do design } \\
\text { da pesquisa }\end{array} \\
\text { - Base de dados } \\
\text { Crunchbase } \\
\text { - Design macro do } \\
\text { estudo }\end{array}$ & $\begin{array}{l}\text { Tratamento da base de dados } \\
\text { - Pré-processamento dos dados } \\
\text { - Transformação e criação de } \\
\text { variáveis }\end{array}$ & $\begin{array}{l}\begin{array}{l}\text { Apresentação e discussão } \\
\text { dos resultados }\end{array} \\
\text { - Análises exploratórias } \\
\text { - Análise dos resultados dos } \\
\text { modelos de predição via } \\
\text { machine learning }\end{array}$ \\
\hline
\end{tabular}

Fonte: Adaptado de Bento (2017, p. 25). 
3.1 Base de dados Crunchbase

Após contatos eletrônicos estabelecidos

com a equipe técnica da plataforma

Crunchbase, sediada nos Estados Unidos, foi

cedido aos autores o acesso aos dados para fins acadêmicos por um período de 6 meses (até outubro de 2020). A Tabela 5 apresenta um resumo de todos os arquivos extraídos da base de dados, em formado CSV (comma-separated values), no dia 29 de junho de 2020.

Tabela 5 - Arquivos Crunchbase

\begin{tabular}{|c|c|c|}
\hline Nome das Tabelas & Observações na Base & No. de Atributos \\
\hline Acquisitions & 103.783 & 27 \\
\hline category_groups & 744 & 9 \\
\hline Checksum & 17 & 3 \\
\hline Degrees & 362.706 & 17 \\
\hline event_appearances & 410.332 & 21 \\
\hline Events & 21.229 & 24 \\
\hline funding_rounds & 325.766 & 15 \\
\hline Funds & 15.243 & 14 \\
\hline investment_partners & 86.124 & 14 \\
\hline Investments & 494.377 & 25 \\
\hline Investors & 149.143 & 27 \\
\hline Ipos & 32.225 & 27 \\
\hline Jobs & 103.783 & 10 \\
\hline org_parents & 15.538 & 9 \\
\hline organization_descriptions & 633.142 & 41 \\
\hline Organizations & 1.064 .929 & 22 \\
\hline People & 1.030 .568 & 9 \\
\hline people_descriptions & 554.512 & 15 \\
\hline
\end{tabular}

Fonte: Adaptado de Crunchbase (2020).

A base de dados possui 18 tabelas, incluindo informações sobre aquisições realizadas (acquisitions), tipos de mercados atingidos pelas startups (category_groups), rodadas de financiamento (funds, funding_rounds), investidores e investimentos (investors, investments, investment_partners),

IPOS realizados (IPOS), pessoas envolvidas nas startups (people, people_descriptions) e dados sobre as próprias startups (organizations, organization_descriptions). Neste estudo, a tabela \#organizations é a base central para consolidação e geração do dataframe final.
Dos 41 atributos da tabela \#organizations, alguns foram descartados por não agregarem valor ao processo de predição do sucesso das startups, tais como: e-mail, número de telefone, urls dos perfis de linkedin, facebook e twitter, endereço, CEP e descrições. O atributo "UUID" (sigla para código de 128 bits denominado Universally Unique Identifier) consiste na chave primária dessa tabela, com valores únicos para identificação de cada startup.

\subsection{Design macro do estudo}

O design deste estudo foi similar ao desenvolvido por Arroyo et al. (2019), com a 
utilização de uma janela temporal para a escolha das startups que fizeram parte do dataset final. A partir da base completa, com 1.064.926 startups, extraída do Crunchbase no dia 29 de junho de 2020, foram filtradas startups com data de fundação entre os dias 29/6/2010 e 29/6/2015, tendo-se assim uma janela de 5 anos para inclusão de startups. Esse período foi denominado janela de aquecimento. Foram incluídas apenas startups que receberam investimentos até a série $\mathrm{C}$, mais especificamente: tipo angel (capital anjo), seed (capital semente), série A e série B.
Adicionalmente aos filtros citados, o fator 'tempo até a primeira rodada de captação' foi inserido, com uma janela máxima de 2 anos após a fundação para a startup captar seu primeiro financiamento. Esse critério buscou aproximar a visão do investidor, que deseja crescimento rápido dos negócios, sendo o tempo para a primeira rodada de investimentos uma variável proxy para a velocidade de atração de recursos.

A Figura 3 mostra o design macro do estudo.

Figura 3 - Design macro do estudo

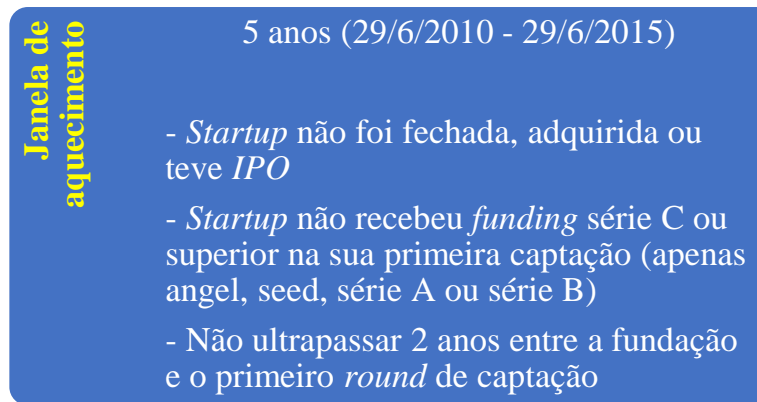

Fonte: Adaptado de Arroyo et al. (2019, p. 124235).

A predição do sucesso das startups mapeadas na janela de aquecimento foi feita entre os dias 30/6/2015 e 29/6/2020. Nesse intervalo, foram identificadas as startups da janela de aquecimento que tiveram sucesso na janela de predição, com a variável target

apresentando 1 (um) se a startup foi adquirida ou realizou IPO (proxy de sucesso neste trabalho), ou 0 (zero), caso contrário. $\mathrm{Na}$ próxima seção é apresentado o processo de tratamento dos dados, em sintonia com o design de pesquisa proposto.

\section{Tratamento da base de dados}

Nesta etapa foi realizado todo o préprocessamento dos dados, incluindo a limpeza da base de dados, transformação e criação de novos atributos, bem como a análise de potenciais outliers. Todas as etapas de tratamento da base de dados foram executadas por meio da linguagem Python de programação.

\subsection{Limpeza inicial da base de dados}

Para a predição do sucesso das startups, alguns atributos se destacaram como potenciais 
variáveis preditoras, a saber: o número de rodadas de financiamento (num_funding_rounds), a categoria/indústria atendida pela startup (category_groups_list), o volume total arrecadado ao longo de todas as rodadas de financiamento recebidas (total_funding_usd), a data de fundação da startup, cuja ausência pode significar um registro equivocado (founded_on), o país de origem (country_code) e a data de sua última rodada de financiamento (last_funding_on)

A Tabela 6 sumariza o processo de limpeza inicial da base de dados.

Tabela 6 - Processo inicial de limpeza da base de dados

\begin{tabular}{|c|c|c|c|}
\hline Etapa da limpeza & $\begin{array}{l}\text { Número de } \\
\text { registros excluídos }\end{array}$ & $\begin{array}{l}\text { Tamanho } \\
\text { da amostra }\end{array}$ & $\%$ \\
\hline BASE DE DADOS ORIGINAL (tabela \#organizations) & & 1.064 .929 & $100 \%$ \\
\hline $\begin{array}{l}\text { Remoção de registros sem o número de rodadas de } \\
\text { financiamento (num_funding_rounds) }\end{array}$ & 890.917 & 174.012 & $16,34 \%$ \\
\hline $\begin{array}{l}\text { Remoção de registros sem o volume total de } \\
\text { financiamento obtido pela startup (total_funding_usd) }\end{array}$ & 47.294 & 126.718 & $11,90 \%$ \\
\hline Remoção de startups sem identificação de nome (name) & 4 & 126.714 & $11,90 \%$ \\
\hline $\begin{array}{l}\text { Remoção de registros sem identificação da data da } \\
\text { última rodada de financiamento (last_funding_on) }\end{array}$ & 0 & 126.714 & $11,90 \%$ \\
\hline $\begin{array}{l}\text { Remoção de startups que não tenham a sua data de } \\
\text { fundação (founded_on) }\end{array}$ & 3.671 & 123.043 & $11,55 \%$ \\
\hline $\begin{array}{l}\text { Remoção de startups sem identificação das indústrias que } \\
\text { atendem (category_groups_list) }\end{array}$ & 2.231 & 120.812 & $11,34 \%$ \\
\hline $\begin{array}{l}\text { Remoção de startups sem identificação do país de origem } \\
\text { (country_code) }\end{array}$ & 454 & 120.358 & $11,30 \%$ \\
\hline $\begin{array}{l}\text { Janela de aquecimento: apenas startups fundadas entre } \\
\text { os dias } 29 / 6 / 2010 \text { e } 29 / 6 / 2015 \text {, que não tenham sido } \\
\text { fechadas nesse período nem recebido rodada de } \\
\text { financiamento série C ou superior }\end{array}$ & 76.483 & 43.875 & $4,12 \%$ \\
\hline $\begin{array}{l}\text { Manutenção apenas de startups com status de empresa, } \\
\text { removendo-se assim as que apresentam status de } \\
\text { investidor ou empresa/investidor }\end{array}$ & 978 & 42.897 & $4,03 \%$ \\
\hline $\begin{array}{l}\text { Retirada de startups com os seguintes investimentos em } \\
\text { sua primeira captação: post ipo equity, post ipo debt, post } \\
\text { ipo secondary e secondary market }\end{array}$ & 221 & 42.676 & $4,01 \%$ \\
\hline $\begin{array}{l}\text { Manutenção apenas de startups com primeiras rodadas } \\
\text { de funding abaixo de série C (angel, seed, series A e series } \\
\text { B) }\end{array}$ & 12.696 & 29.980 & $2,82 \%$ \\
\hline $\begin{array}{l}\text { Retirada de startups com data de fundação "posterior" } \\
\text { ao primeiro round de captação }\end{array}$ & 2.083 & 27.897 & $2,62 \%$ \\
\hline $\begin{array}{l}\text { Manutenção apenas de startups com tempo até a } \\
\text { primeira rodada de captação inferior a } 720 \text { dias ( } 2 \text { anos) }\end{array}$ & 9.336 & 18.561 & $1,74 \%$ \\
\hline $\begin{array}{l}\text { TAMANHO DA AMOSTRA APÓS LIMPEZA } \\
\text { INICIAL }\end{array}$ & & 18.561 & $1,74 \%$ \\
\hline
\end{tabular}

Fonte: Elaborado pelos autores (2021).

Decidiu-se também excluir 978 startups que apresentam status de investidora ou status híbrido, ou seja, empresa e investidora.

Dessa forma, foram mantidas no estudo apenas startups que não vinculem atividades de investimento ao seu core business. Além disso, após análise das formas de captação no primeiro 
funding, decidiu-se excluir startups com financiamentos típicos de empresas já maduras, como rodadas após um IPO e ligadas a captação via mercado mobiliário.

Após a limpeza inicial dos dados, chegou-se a 18.561 startups com dados em todos os atributos e que atendiam aos critérios estabelecidos na janela de aquecimento. Dando seguimento à etapa de pré-processamento dos dados, decidiu-se excluir da tabela \#organizations colunas (atributos) sem aderência ao estudo.

\subsection{Transformação e criação de novos atributos}

Transformações e novas features foram criadas a partir das tabelas \#organizations, \#funding_rounds e \#people para melhor caracterizar as rodadas de financiamento, as indústrias atendidas pelas startups, os locais de origem e o atributo-alvo (target).

O critério para a escolha e criação de atributos considerou atributos preditivos aderentes ao universo e cenário competitivo das startups. Foram considerados atributos importantes para os investidores, dentro do horizonte temporal proposto no estudo: valor do primeiro funding, tempo entre funding rounds, número de rodadas de investimento, número de colaboradores, número de mercados atendidos, país de origem e principal indústria.

A Tabela 7 mostra o esquema dos novos atributos.

Tabela 7 - Visão geral dos novos atributos

\begin{tabular}{|l|l|c|c|}
\hline \multicolumn{1}{|c|}{ Rodadas de Financiamento } & Indústrias atendidas & $\begin{array}{c}\text { Local de } \\
\text { origem }\end{array}$ & $\begin{array}{c}\text { Atributo-alvo } \\
\text { (target) }\end{array}$ \\
\hline $\begin{array}{l}\text { - Tempo até a primeira rodada de } \\
\text { financiamento }\end{array}$ & $\begin{array}{l}\text { - Categoria principal } \\
\text { - Número de indústrias } \\
\text { atendidas }\end{array}$ & $\begin{array}{l}\text { - Região } \\
\text { de } \\
\text { origem }\end{array}$ & $\begin{array}{l}\text { Sucesso (ou } \\
\text { não) da startup }\end{array}$ \\
$\begin{array}{l}\text { - Valor da primeira rodada de captação } \\
\text { - Tipo da primeira rodada de financiamento }\end{array}$ & & & \\
\hline
\end{tabular}

Fonte: Elaborado pelos autores (2021).

Sobre as rodadas de financiamento, decidiu-se explorar:

- O tempo até a primeira rodada de financiamento como proxy da velocidade de atração de recursos para a startup. Essa variável foi operacionalizada pela diferença entre

a data da primeira rodada de financiamento e a data de fundação da startup. A data do primeiro funding foi obtida pela manipulação prévia da tabela \#funding_rounds.

- O tempo médio entre rodadas também permite visualizar o espaçamento temporal da ação dos investidores junto às startups. Essa variável foi operacionalizada com dados da tabela \#organizations, sendo o intervalo entre a última rodada de financiamento ('last_funding_on) e a data de fundação da startup ('founded_on) dividido pela 
quantidade de funding rounds obtidos pela startup ('num_funding_rounds).

- O valor da primeira rodada de captação se relaciona à capacidade de atração inicial de capital. Valores mais altos podem indicar que os investidores possuem uma visão otimista sobre o futuro da startup. Esse valor foi obtido pelo valor do primeiro funding de cada startup na tabela \#funding_rounds, coletando-se a variável 'raised_amount_usd'.

- As startups são financiadas de diversas formas, sendo capital semente (seed), investimento anjo (angel) e série A prevalentes na primeira rodada de financiamento das startups encontradas na plataforma Crunchbase, com destaque para o capital semente $(75,52 \%)$. A criação dessa variável teve $\mathrm{o}$ intuito de averiguar se distintas formas de captação inicial desempenham papéis diferenciados para a predição do sucesso de startups.

Para as indústrias atendidas:

- Inicialmente, vale destacar que o atributo 'category_groups_list', na tabela \#organizations, tinha 9.955 valores únicos, os quais foram identificados na fase de préprocessamento com o uso da linguagem de programação Python. Esses 9.950 valores são derivados de diversas combinações entre as 43 indústrias representadas na plataforma Crunchbase. As cinco indústrias com maior número de startups na amostra são: commerce and shopping, apps, financial services, data and analytics, e advertising; somadas representam $40 \%$ das startups. Nota-se grande concentração entre um e cinco mercados atendidos, ou ao menos declarados como potenciais mercados consumidores pelas próprias startups na plataforma Crunchbase.

- Similar ao trabalho de Bento (2017), a categoria principal se refere ao foco do posicionamento do negócio da startup, ou seja, primeira indústria declarada como proxy de seu core business.

- O número de indústrias atendidas refere-se à quantidade de indústrias que cada startup declara atender com seu modelo de negócios. Essa variável pode ser considerada como proxy da diversificação mercadológica de cada startup.

Sobre os locais de origem, decidiu-se pela seguinte transformação:

- A base de dados limpa possui startups de 141 países. Estados Unidos e Europa, com 8.267 e 4.619, respectivamente, representam cerca de $70 \%$ de todas as startups deste estudo. Dessa forma, decidiu-se agrupar os 
países pelo seu continente de origem, com exceção dos Estados Unidos, China (que sozinha representa quase 9\% da amostra), e Brasil (pela condução das etapas da pesquisa em território brasileiro). A Figura 4 mostra a distribuição das startups após a transformação do atributo 'country_code' em continentes de origem.

Figura 4 - Locais de origem das startups

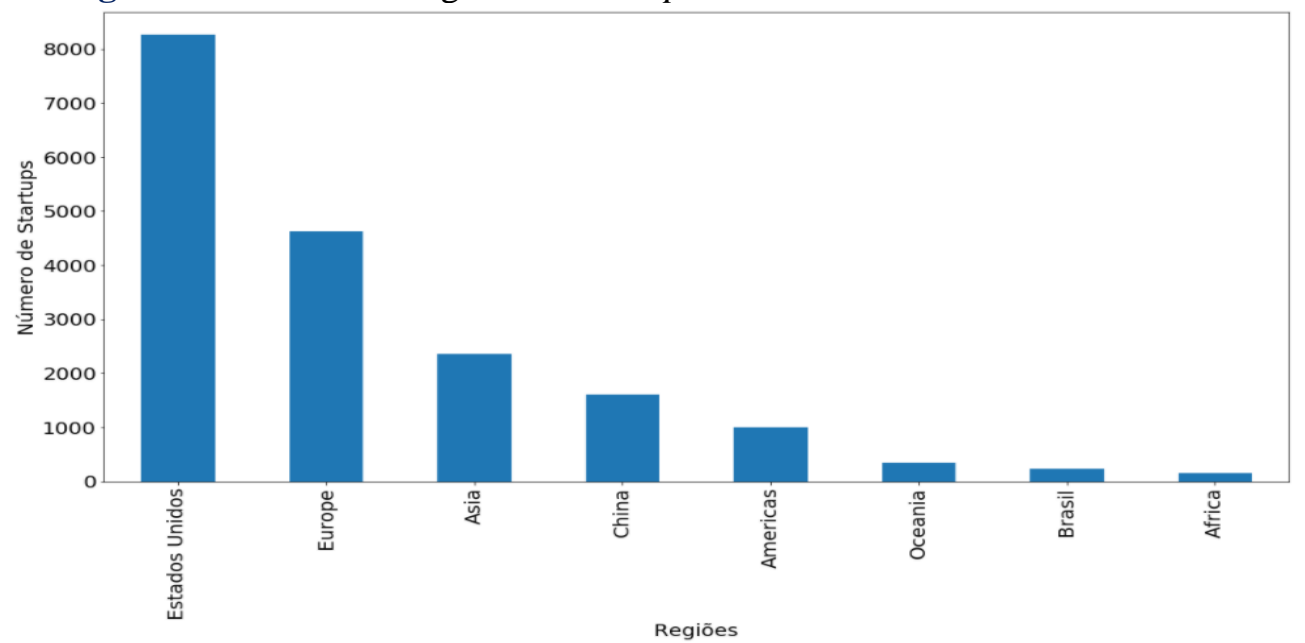

Fonte: Elaborado pelos autores (2021).

Quanto à variável que se deseja predizer (target), decidiu-se pela seguinte operacionalização, de acordo com o objetivo do estudo:

- Startups que conseguiram fazer um processo de IPO ou foram adquiridas serão relacionadas à "Classe 1", ou seja, denominadas com bem-sucedidas de acordo com o design desta pesquisa.
Startups ainda em operação, mas sem $I P O$ ou aquisição serão alocadas para a "Classe 0" (sem sucesso, ao menos ainda).

Conforme se observa na Figura 5, a amostra comporta menos de $1 \%$ de startups que fizeram IPO. Tem-se $11,59 \%$ de startups bemsucedidas pelo critério de sucesso estabelecido neste estudo, caracterizando um

problema de classificação com dados desbalanceados. 
Figura 5 - Status das startups

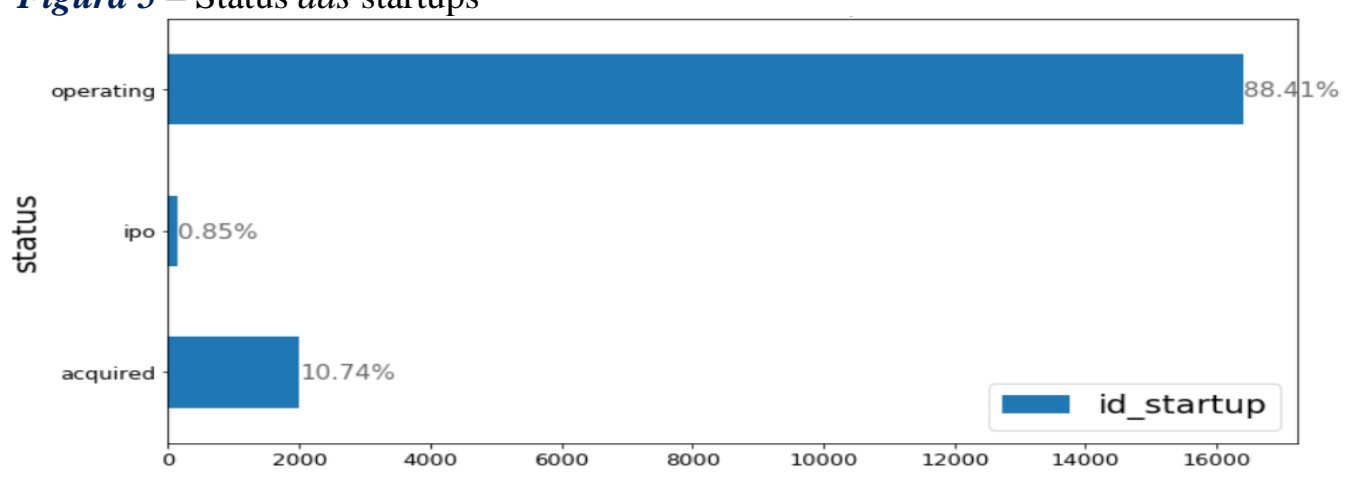

Fonte: Elaborado pelos autores (2021).

A Tabela 8 mostra os atributos do dataset da pesquisa após o processo de transformação e criação de novas features.

Tabela 8 - Atributos após transformações e criação de novas features

\begin{tabular}{|c|c|c|}
\hline Atributo & Descrição & Tipo \\
\hline Uuid & $\begin{array}{l}\text { Código único para identificação de cada startup (chave primária da tabela } \\
\text { \#organizations) }\end{array}$ & Nominal \\
\hline Name & Nome da startup & Nominal \\
\hline categoria_principal & $\begin{array}{l}\text { Identificação do posicionamento mercadológico da startup, ou seja, a } \\
\text { indústria principal que declara atender }\end{array}$ & Categórica \\
\hline $\begin{array}{l}\text { new_num_ } \\
\text { mercados }\end{array}$ & $\begin{array}{l}\text { Diversidade declarada de indústrias atendidas pelo modelo de negócio da } \\
\text { startup }\end{array}$ & Categórica \\
\hline $\begin{array}{l}\text { num_- } \\
\text { colaboradores }\end{array}$ & $\begin{array}{l}\text { Número de colaboradores informados na plataforma. Essa variável é } \\
\text { apresentada em faixas, por exemplo: } 1-10 \text { funcionários. Apenas mudança } \\
\text { do nome do atributo 'employee_count'. }\end{array}$ & Categórica \\
\hline $\begin{array}{l}\text { num_funding_ } \\
\text { rounds }\end{array}$ & $\begin{array}{l}\text { Número total de rodadas de financiamento recebidas ao longo da trajetória } \\
\text { da startup }\end{array}$ & Numérica \\
\hline $\begin{array}{l}\text { tipo_investimento_ } \\
\text { primeiro_funding }\end{array}$ & $\begin{array}{l}\text { Tipo de captação recebida na primeira rodada de financiamento da startup } \\
\text { (por exemplo: seed, angel, series } \mathrm{A} \text {, series } \mathrm{B} \text {, etc) }\end{array}$ & Categórica \\
\hline $\begin{array}{l}\text { valor_primeiro_ } \\
\text { funding }\end{array}$ & Valor recebido pela startup em sua primeira captação (em US\$) & Numérica \\
\hline $\begin{array}{l}\text { tempo_ate_ } \\
\text { primeiro_round }\end{array}$ & $\begin{array}{l}\text { Tempo transcorrido (em dias) entre a fundação da startup e seu primeiro } \\
\text { round de captação }\end{array}$ & Numérica \\
\hline $\begin{array}{l}\text { tempo_medio_ } \\
\text { entre_fundings }\end{array}$ & Tempo médio (em dias) entre as rodadas de captação recebidas pela startup & Numérica \\
\hline regiao_startup & $\begin{array}{l}\text { Continentes de origem da startup, com exceção dos Estados Unidos e } \\
\text { China, pela representatividade destes na base de dados, e do Brasil, pela } \\
\text { pesquisa ser conduzida em território brasileiro }\end{array}$ & Categórica \\
\hline status_su & $\begin{array}{l}\text { Classe } 1 \text { para startups com } I P O \text { ou adquiridas, significando sucesso no } \\
\text { presente estudo. Classe } 0 \text { se seguem em operação, mas ainda sem aquisição } \\
\text { ou } I P O \text { dentro da janela de simulação. }\end{array}$ & $\begin{array}{c}\text { Binária } \\
(0,1)\end{array}$ \\
\hline
\end{tabular}

Fonte: Elaborado pelos autores (2021).

\section{Apresentação e discussão dos resultados}

Este item apresenta análises exploratórias sobre o sucesso na amostra de
18.561 startups, bem como os modelos de predição via machine learning e seus resultados. 


\subsection{Análise exploratória}

Algumas análises exploratórias já foram realizadas na seção sobre Tratamento dos Dados. Nesta seção, a exploração dos dados avançará nas seguintes dimensões: a) Análise descritiva das variáveis numéricas; b) Análise de correlação entre as variáveis numéricas do dataset final; c) Análise de dispersão com visualização de startups bem-sucedidas (Classe
1) e sem sucesso (Classe 0); e d) Análise percentual da distribuição de startups em operação e adquiridas/IPOs, por indústria principal atendida

Com isso, pretende-se visualizar a existência de padrões prévios antes da rodagem dos modelos de machine learning para classificação binária.

Tabela 9 - Análise descritiva inicial (variáveis numéricas do conjunto de dados final)

\begin{tabular}{|l|c|c|c|c|c|}
\hline \multicolumn{1}{|c|}{ Atributo Numérico } & Média & $\begin{array}{c}\text { Desvio } \\
\text { padrão }\end{array}$ & $\begin{array}{c}\text { Coeficiente } \\
\text { de Variação }\end{array}$ & Mínimo & Máximo \\
\hline New_num_mercados & 3,51 & 1,73 & $49,29 \%$ & 1 & 14 \\
\hline Num_funding_rounds & 2,57 & 1,81 & $70,43 \%$ & 1 & 22 \\
\hline Valor_primeiro_funding (US\$) & 1.792 .994 & 13.956 .656 & $778,40 \%$ & 468 & 1.080 .000 .000 \\
\hline Tempo_ate_primeiro_round (dias) & 309 & 196 & $63,43 \%$ & 1 & 719 \\
\hline Tempo_medio_entre_funding (dias) & 380 & 205 & $53,95 \%$ & 1 & 1579 \\
\hline
\end{tabular}

Fonte: Elaborado pelos autores (2021).

A Tabela 9 apresenta uma análise descritiva das variáveis numéricas do dataset. Notam-se dados enviesados à direita nas variáveis numéricas, principalmente no valor da primeira rodada de financiamento. Não foram realizadas discretização dos dados e retirada de potenciais outliers, como fez Bento (2017), pois assume-se que os valores são possíveis dentro do cenário de investimentos em startups e que, por isso, podem ser mantidos nos modelos de predição.

Figura 6 - Correlação das variáveis numéricas

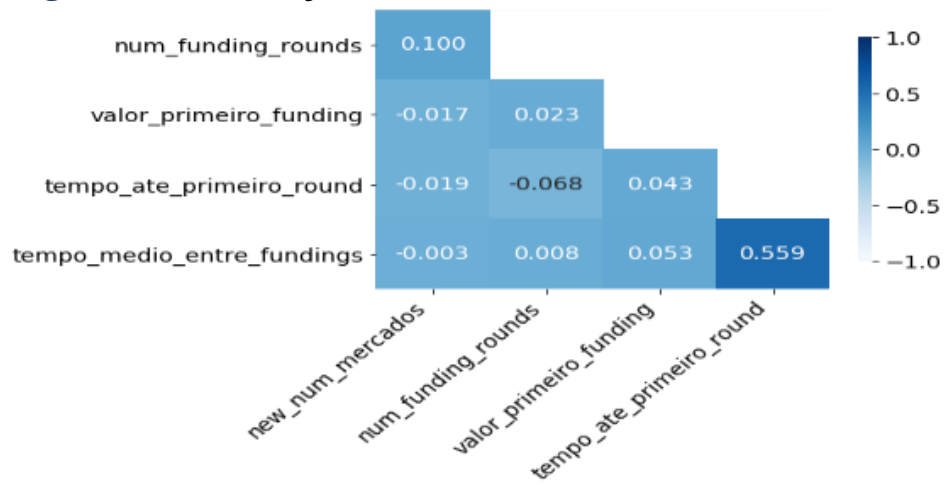

Fonte: Elaborado pelos autores (2021).

A Figura 6 apresenta uma análise de correlação entre os atributos preditivos numéricos. A correlação mais intensa foi entre o tempo até a primeira rodada de captação e o 
tempo médio entre funding rounds $(0,559)$. As demais relações não apresentam correlação aparente, demonstrando baixa multicolinearidade entre as variáveis preditivas.
Os gráficos de dispersão com pares de atributos preditivos (Figura 7) não apresentam clara distinção entre startups Classe 0 e Classe 1 (sucesso).

Figura 7 - Análise de dispersão
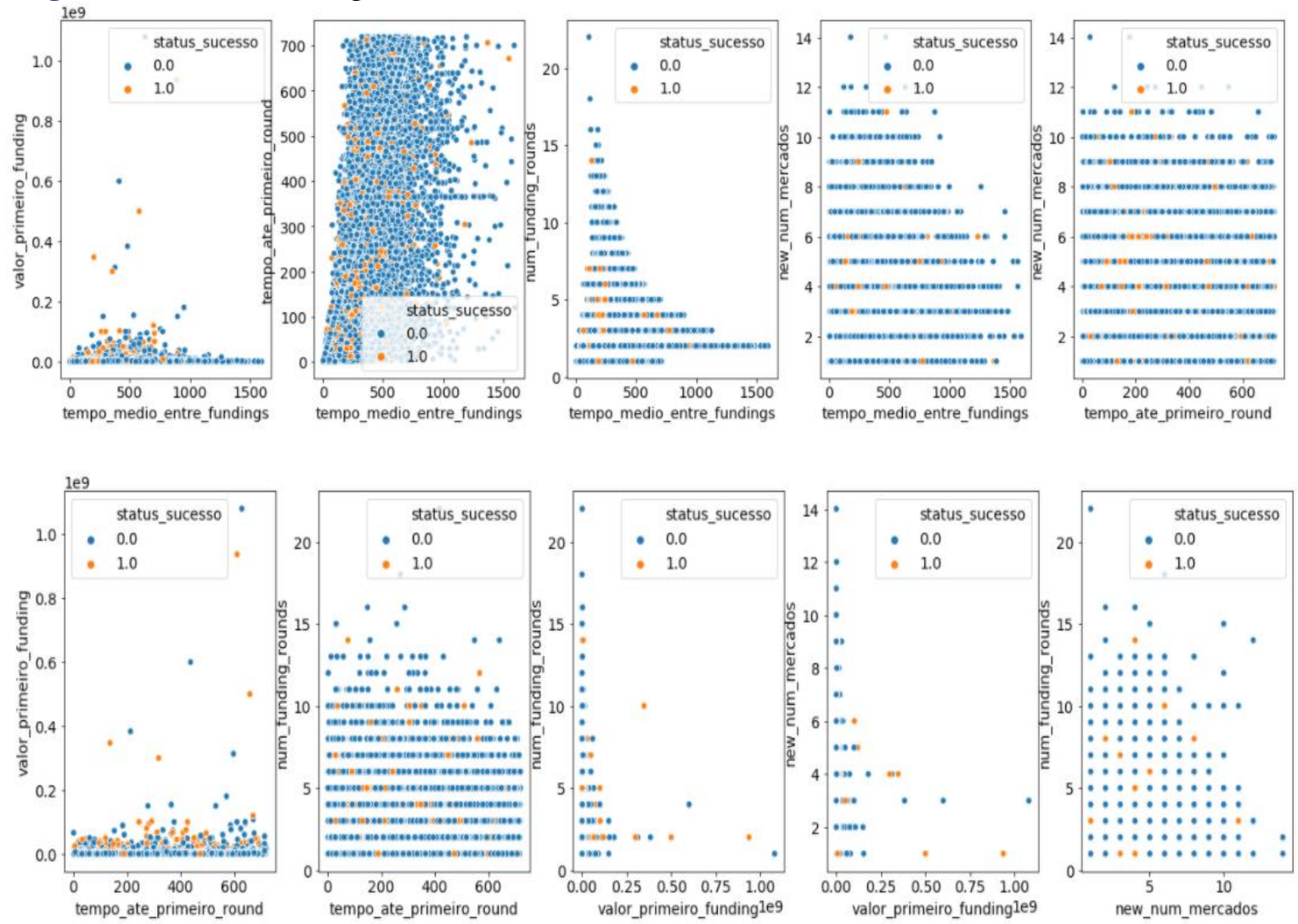

Fonte: Elaborado pelos autores (2021).

Essa dificuldade de distinguir entre as variáveis preditoras e a variável target é mais um incentivo para se tentar modelos de machine learning que busquem auxiliar a tarefa de classificação binária.

Ainda na fase de exploração de distribuição do percentual de startups bemsucedidas (IPO + Aquisição), startups com IPO e startups adquiridas, nas 10 indústrias mais representativas da amostra - cerca de 63\% das 18.561 startups. potenciais padrões, a Tabela 10 apresenta a 
Tabela 10 - Distribuição das startups por status (top 10 indústrias na amostra)

\begin{tabular}{|c|c|c|c|c|}
\hline Indústria & $\begin{array}{c}\text { Número de } \\
\text { Startups }\end{array}$ & $\%$ sucesso & $\begin{array}{c}\text { \% sucesso via } \\
\text { IPO }\end{array}$ & $\begin{array}{c}\text { \% sucesso via } \\
\text { Aquisição }\end{array}$ \\
\hline Commerce and Shopping & 2435 & 11,01 & 0,49 & 10,51 \\
\hline Apps & 2069 & 11,79 & 0,68 & 11,12 \\
\hline Financial Services & 1072 & 11,10 & 0,75 & 10,35 \\
\hline Data and Analytics & 978 & 18,71 & 0,10 & 18,61 \\
\hline Advertising & 911 & 13,94 & 0,55 & 13,39 \\
\hline Information Technology & 881 & 13,28 & 0,23 & 13,05 \\
\hline Artificial Intelligence & 878 & 13,67 & 0,23 & 13,44 \\
\hline Health Care & 870 & 9,08 & 0,69 & 8,39 \\
\hline Consumer Electronics & 827 & 9,07 & 0,60 & 8,46 \\
\hline Internet Services & 804 & 11,94 & 0,75 & 11,19 \\
\hline
\end{tabular}

Fonte: Elaborado pelos autores (2021).

Da lista das 10 principais indústrias, nenhuma ultrapassou $20 \%$ de sucesso na janela de simulação (média de 11,59\%). Destacam-se startups voltadas para Data and Analytics, com $18,71 \%$ de sucesso. Verifica-se também que o sucesso, independentemente da indústria, provém mais dos processos de aquisição do que de $I P O$. Dentre as 47 indústrias presentes no dataset, nenhuma ultrapassou a taxa de sucesso de $20 \%$ dentro da janela de simulação deste estudo, exceto Platforms com apenas 2 startups.

\subsection{Modelos de classificação binária via machine learning}

Os algoritmos selecionados para a tarefa de predição do sucesso de startups seguiram a maioria dos modelos descritos na
Tabela 2 da revisão da literatura, sendo eles: Regressão Logística (baseline), Decision tree, Random Forest, XGBoost: Extreme Gradient Boosting, SVM: Support Vector Machine e Rede neural (MLP: Multi-Layer Perceptron).

O dataset é altamente desbalanceado, com 16.409 registros alocados na Classe 0 e 2.152 na Classe 1, indicando uma proporção de desbalanceamento de 7,62:1. Como o interesse é a predição da classe minoritária, optou-se por tratar o desbalanceamento usando o objeto RandomOverSample da biblioteca Imblearn do Python, apenas nos dados de treinamento. Random oversampling consiste na seleção de exemplos da classe minoritária, com substituição e adição destes ao conjunto de dados de treinamento. Os dados foram balanceados após a separação do dataset em dados para treinamento (80\%) e dados para teste 
(20\%), com estratégia de partição balanceada dos registros.

Para a rodagem dos modelos, criou-se um pré-processador para a preparação dos dados, incluindo one-hot encoder para transformação das variáveis categóricas, e normalização das numéricas com MinMaxScaler. Esse pré-processador foi utilizado nos pipelines do Python para rodagem dos modelos. Todos os modelos tiveram validação cruzada com 5 folds. Além disso, buscou-se realizar tunning dos seus hiperparâmetros por meio da função GridSearch do Python. A Tabela 11 apresenta os melhores parâmetros de cada modelo após o processo de tunning.

Tabela 11 - Melhores parâmetros dos modelos

Modelos

Regressão logística (RL)
Decision Tree $(D T)$
Random Forest $($ RF $)$
XGBoost $(X G)$
Support Vector Machine
$($ SVM $)$

Redes Neurais $(\mathrm{RN})$
Parâmetros testados

$\mathrm{C}:[1,2,3,4,5,6,7,8,9,10]$ max_depth: $[3,4,5,6,7,9,11,13,15,17]$ max_depth: $[3,4,5,6,7,9,11,13,15]$ learning_rate: $[0.01,0.015,0.02,0.04,0.06]$ C: $[0.1,1,10,100]$

Gamma: [1, 0.1, 0.01, 0.001], kernel: ['rbf'] alpha: [0.1, 0.01, 0.02], hidden_layer_sizes: $[3,5,15,25,50,100,1000]$
Melhores parâmetros (via GridSearch)

$\mathrm{C}=3$

Tree max. depth $=17$

Random Forest max. depth $=15$ learning rate $=0,06$

$\mathrm{C}=10$

Gamma $=0,1$

kernel $=\mathrm{Rbf}$

alpha $=0,01$

hidden layer sizes $=1000$

Fonte: Elaborado pelos autores (2021).

\subsection{Resultados dos modelos de classificação}

A Tabela 12 apresenta as principais medidas de avaliação do modelo para cada classe: precisão, recall, fl-score e AUC (Area Under the Curve).

Tabela 12 - Índices para avaliação dos modelos de classificação

\begin{tabular}{|c|c|c|c|c|c|c|c|c|c|c|}
\hline \multirow{2}{*}{ Modelo } & \multirow{2}{*}{ AUC } & \multirow{2}{*}{ Acurácia } & Acurácia & \multirow{2}{*}{ balanceada } & GMean & \multicolumn{3}{|c|}{ Classe 0 } & \multicolumn{3}{c|}{ Classe 1 (sucesso) } \\
\cline { 6 - 12 } & & & Precisão & Recall & F1 & Precisão & Recall & F1 \\
\hline RL & 0,638 & 0,628 & 0,638 & 0,638 & 0,93 & 0,63 & 0,75 & 0,19 & 0,65 & 0,29 \\
\hline$D T$ & 0,586 & 0,711 & 0,586 & 0,563 & 0,91 & 0,75 & 0,82 & 0,18 & 0,42 & 0,25 \\
\hline$R F$ & 0,663 & 0,779 & 0,669 & 0,645 & 0,93 & 0,81 & 0,87 & 0,26 & 0,51 & 0,35 \\
\hline$X G$ & 0,671 & 0,715 & 0,671 & 0,669 & 0,94 & 0,73 & 0,82 & 0,23 & 0,61 & 0,33 \\
\hline$S V M$ & 0,634 & 0.592 & 0,634 & 0,631 & 0,93 & 0,58 & 0,71 & 0,18 & 0,69 & 0,28 \\
\hline RN & 0,613 & 0,733 & 0,613 & 0,592 & 0,92 & 0,65 & 0,84 & 0,21 & 0,46 & 0,28 \\
\hline
\end{tabular}

Fonte: Elaborado pelos autores (2021).

Os classificadores que se destacaram, em termos gerais, foram o Extreme Gradient Boosting (XG) e o Random Forest (RF),

Figura 8 - Curvas ROC dos modelos analisados considerados como classificadores conjuntos (ensemble classifiers). Tais resultados seguiram a mesma direção do estudo conduzido por Arroyo et al. (2019). 


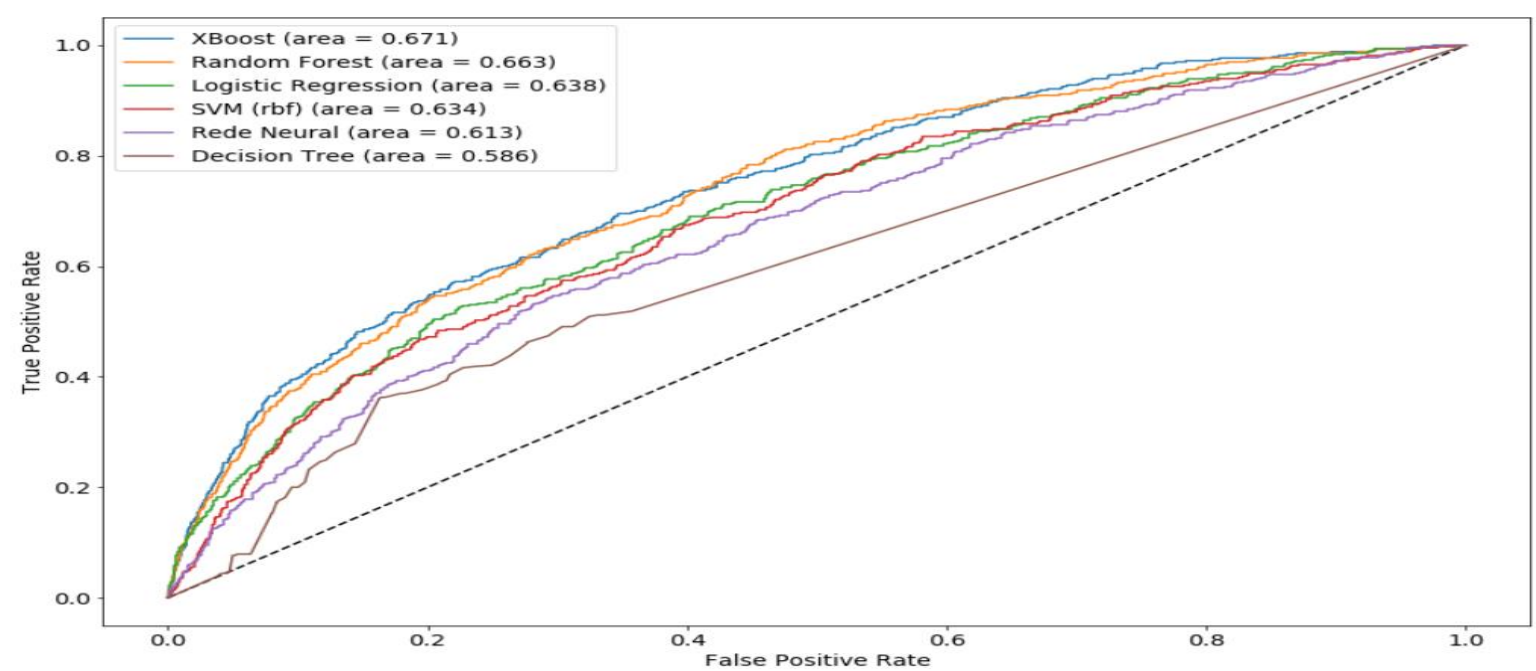

Fonte: Elaborado pelos autores (2021).

O índice AUC (Area Under the Curve), que considera a área sob a curva em um gráfico que relaciona a taxa de falsos positivos (especificidade) e a taxa de verdadeiros positivos (sensibilidade), ficou em quase $70 \%$ $(0,671)$ no caso do Extreme Gradient Boosting, e 0,663 para o Random Forest, que se destacaram entre os classificadores (vide Figura 8).

Os classificadores $S V M$ e $D T$ tiveram menor índice $A U C$. Na acurácia balanceada, os mesmos classificadores tiveram destaque $(X G=$ $0,671$ e $R F=0,663)$.

Para o objetivo deste estudo, a precisão por classe, principalmente da classe minoritária (sucesso das startups) é o índice mais importante, pois indica o percentual de verdadeiros positivos no total de registros classificados como positivos. Os classificadores tiveram precisão entre $0,18 \mathrm{e}$ 0,26 para classificação na Classe 1 . Destacaram-se $X G$ e $R F$, com $23 \%$ e $26 \%$, respectivamente.

A escolha de um melhor classificador é complexa, pois um único índice não engloba todas as possibilidades de análise. Também depende do objetivo de cada estudo. A Tabela 13 apresenta um conjunto de índices para a análise conjunta dos dois melhores classificadores neste estudo.

Tabela 13 - Análise comparativa XG e RF

\begin{tabular}{|c|c|c|c|c|}
\hline Classificador & $A U C$ & $T P R($ Recall $)$ & $F N R$ & Precisão \\
\hline$R F$ & 0,663 & $51,2 \%$ & $18,6 \%$ & $26,4 \%$ \\
\hline$X G$ & 0,671 & $61,4 \%$ & $27,1 \%$ & $22,9 \%$ \\
\hline
\end{tabular}

Fonte: Elaborado pelos autores (2021). 
Como o Recall (razão entre o número de startups classificadas na Classe 1 pelo número total de startups que, de fato, foram bem-sucedidas) é menos relevante para o presente estudo, pois números acima de $50 \%$ demonstram uma boa classificação de startups elegíveis para investimentos bem-sucedidos, o foco recairá na Precisão. Nesse quesito sobressaiu o classificador Random Forest com uma precisão de 26,4\% (com menor FNR False Negative Rate, indicando menor probabilidade de indicação aos investidores de startups com menor potencial de sucesso).

Em rápida análise, os números parecem baixos, mas vale lembrar que o índice médio de sucesso entre as 18.571 startups da amostra é de $11,59 \%$. Tomando-se como exemplo a precisão do modelo Random Forest (26,4\%), alcança-se uma melhoria de $128 \%$ frente aos $11,59 \%$ (média de sucesso das startups). Do ponto de vista do investidor, o filtro gerado pelo classificador coloca a proporção de escolha de startups para funding em uma proporção de 3,8 para 1, ou seja, chance de sucesso de 1 startup para cada 3,8 startups adicionadas ao portfólio do investidor.

Esse resultado (26,4\%), mesmo com diferenças no design de pesquisa e tratamento dos dados, é próximo ao obtido por Arroyo et al. (2019), que alcançou uma precisão de 33\% para aquisição de startups (modelo Random Forest) e $44 \%$ para IPO (modelo Random Forest).
Vale também destacar dois pontos do design de pesquisa que podem colaborar para atingir taxas de precisão dessa magnitude:

a) $\mathrm{O}$ processo de tratamento de dados desta pesquisa foi bastante rígido quando comparado aos estudos apresentados na Tabela 2. Decidiuse eliminar todos os registros (startups) com ausência de valores nos atributos preditores (ver Tabela 8 para mais detalhes). Essa decisão foi motivada pela análise exploratória dos dados e pela própria natureza dos dados presentes na plataforma Crunchbase. Como existe autodeclaração dos dados na plataforma, decidiu-se apenas pela manutenção de startups com dados em todos os atributos, minimizandose $\operatorname{assim}$ a inclusão de registros falhos.

Essa decisão segue a premissa de que startups com dados completos, em todas as features analisadas, possuem informações mais confiáveis.

b) Foram incluídos atributos preditivos que tivessem consistência com o universo e o cenário competitivo das startups, conforme mostra a Tabela 8. Alguns estudos anteriores incluíram informações indicadas na plataforma Crunchbase de baixa relevância para os investidores, como existência ou não de perfil Linkedin/Facebook, contato 
telefônico ou mesmo e-mail, (Arroyo et al. 2019). Tais fatores não agregam diferenciais competitivos às startups, mesmo que - eventualmente - possam trazer algum tipo de melhoria nos modelos de classificação.
Os modelos baseados em árvores, também chamados de White-Box Models, possibilitam a análise da importância dos atributos (features) no modelo de classificação.

Tabela 14 - Importância dos atributos (feature importance)

\begin{tabular}{cl|cl}
\hline \multicolumn{1}{c|}{ Random Forest $(\boldsymbol{R F})$} & \multicolumn{1}{c}{ Extreme Gradient Boosting $(\boldsymbol{X G})$} \\
\hline Peso & \multicolumn{1}{c}{ Atributo } & Peso & Atributo \\
\hline $\mathbf{1 9 , 3 8 \%}$ & Valor_primeiro_funding & $\mathbf{1 0 , 8 3 \%}$ & Região_startup_Estados Unidos \\
\hline $\mathbf{1 4 , 1 1 \%}$ & Tempo_medio_entre_fundings & $\mathbf{3 , 6 2 \%}$ & Valor_primeiro_funding \\
\hline $\mathbf{1 0 , 7 3 \%}$ & Tempo_ate_primeiro_funding & $\mathbf{2 , 8 2 \%}$ & Num_colaboradores_1-10 \\
\hline $\mathbf{7 , 5 7 \%}$ & Num_funding_rounds & $\mathbf{2 , 7 8 \%}$ & Num_funding_rounds \\
\hline $\mathbf{6 , 1 1 \%}$ & Região_startup_Estados Unidos & $\mathbf{2 , 7 7 \%}$ & Região_startup_China \\
\hline $\mathbf{5 , 4 2 \%}$ & New_num_mercados & $\mathbf{2 , 6 9 \%}$ & Num_colaboradores_11-20 \\
\hline $\mathbf{3 , 0 4 \%}$ & Num_colaboradores_1-10 & $\mathbf{2 , 6 5 \%}$ & Tipo_investimento_primeiro_funding_series_a \\
\hline $\mathbf{2 , 3 1 \%}$ & Tipo_investimento_primeiro_funding_series_a & $\mathbf{2 , 3 6 \%}$ & Tipo_investimento_primeiro_funding_angel \\
\hline $\mathbf{2 , 0 3 \%}$ & Tipo_investimento_primeiro_funding_angel & $\mathbf{1 , 8 9 \%}$ & Categoria_principal_Data and Analytics \\
\hline $\mathbf{1 , 9 1 \%}$ & Região_startup_China & $\mathbf{1 , 8 5 \%}$ & Categoria_principal_Apps \\
\hline
\end{tabular}

Fonte: Elaborado pelos autores (2021).

De forma geral, os atributos mais valorizados pelos dois modelos baseados em árvores são semelhantes. Os dez atributos mais importantes no modelo Random Forest explicam 72,61\% da classificação, enquanto no modelo Extreme Gradient Boosting, apenas $34,26 \%$, indicando maior dispersão explicativa dos atributos.

$\mathrm{O}$ valor da primeira captação ocupa a primeira ou segunda posição nos classificadores. Como país de origem da startup, os Estados Unidos se destacam no modelo $X G$, com a China ocupando a quinta posição. Aliás, Estados Unidos e China são atributos preditivos relevantes nos dois modelos $(X G$ e $R F)$. Destaca-se também a natureza da primeira rodada de captação ser do tipo série A, um indicativo da importância de valores iniciais maiores para uma caminhada bem-sucedida da startup.

A variável "new_num_mercados", relacionada à diversidade de mercados atendidos (autodeclaração das startups), não se mostrou relevante para o classificador $X G$, apenas para o $R F$. Já a quantidade de colaboradores ("num_colaboradores") teve presença nos dois, em faixas baixas no $R F$ e desconhecida no $X G$, indicando que startups bem-sucedidas contam com um número menor de colaboradores.

A questão do tempo de funding, tanto o período médio entre rodadas de captação quanto o tempo decorrido entre a criação da startup e sua primeira captação, não se mostrou relevante no modelo $X G$. Por outro lado, a questão temporal teve grande relevância no modelo de 
classificação $R F$, ocupando a segunda e terceira colocação.

Interessante notar a baixa incidência do atributo caracterizador da principal indústria atendida pela startup no classificador $R F$. Esse achado é contraintuitivo, pois a literatura de negócios indica forte associação entre o tipo de indústria e sua capacidade de ser atrativa na geração de resultados financeiros positivos (Porter, 2005). No caso do $X G$, a indústria de Data and Analytics está entre os dez atributos mais relevantes. Vale lembrar que essa indústria detém o maior percentual de startups bemsucedidas na amostra, $18.71 \%$.

No estudo de Arroyo et al. (2019), outras variáveis se mostraram mais importantes nos modelos $R F$ e $X G$, como idade da startup, ter um perfil ativo no LinkedIn, a quantidade de

\section{Considerações finais}

Este trabalho, inspirado pelo design de pesquisa com janelas temporais proposto por Arroyo et al. (2019), analisou seis modelos de machine learning para a predição do sucesso de startups, a saber: Regressão Logística, Decision Tree, Random Forest, Extreme Gradient Boosting, Support Vector Machine, e Redes Neurais.

Modelo de redes neurais do tipo multi layer perceptron, pouco usado na tarefa de prever o sucesso de startups (vide Tabela 2), mostrou-se promissor para estudos futuros. No presente estudo, gerou $21 \%$ de precisão, ocupando a terceira posição na medida de avaliação entre os classificadores testados. fundadores, número de telefone e e-mail informado na plataforma Crunchbase, o valor total arrecadado nas rodadas de financiamento; e posicionamento da startup nas indústrias de saúde, ciência e engenharia, no caso do modelo $X G$. No presente estudo, diferentes indústrias, como Data Analytics e Apps, explicam os resultados do modelo $X G$, potencialmente demonstrando a velocidade das mudanças e reorientação de investimentos no ecossistema empreendedor. Além disso, conforme mencionado no capítulo introdutório, variáveis pouco relevantes para investidores que foram introduzidas como preditoras no modelo de Arroyo et al. (2019) mostraram-se relevantes para a explicação dos modelos de predição, como a inclusão de perfil no LinkedIn, e-mail e telefone na plataforma Crunchbase.

Este estudo incluiu apenas startups fundadas entre junho de 2010 e junho de 2015 , utilizando um conceito de janela temporal similar ao design do estudo de Arroyo et al. (2019). Com isso, buscou-se minimizar o viés de sobrevivência das startups inseridas no dataset final, bem como dados inconsistentes pela natureza retroativa da inserção de dados. Bento (2017), por exemplo, utilizou startups americanas fundadas entre 1985 e 2014 , data bastante anterior à criação da plataforma Crunchbase.

Os modelos que, no geral, tiveram melhores índices foram os baseados em ensembles de árvores: o Extreme Gradient Boosting (XG) com AUC de 0,671 e o Random Forest, com 0,663. Algoritmos do tipo 
ensemble classifiers, ou de aprendizado conjunto, também se destacaram nos estudos de Bento (2017), Pan, Gao e Luo (2018) e Arroyo et al. (2019).

$\mathrm{O}$ classificador Random Forest atingiu uma Taxa de Verdadeiros Positivos de 51,2\% e Taxa de Falsos Negativos de 18,6\%. A precisão do $R F$ para classificar corretamente a Classe 1 , ou seja, startups bem-sucedidas, foi de $26,4 \%$ (superior ao $X G$, que obteve $22,9 \%$ de precisão).

Em vista da quantidade de dados faltantes na plataforma Crunchbase, a estratégia conservadora usada neste estudo para tratá-los considerou apenas startups com valores presentes em todos os atributos preditivos. Além disso, conforme a Tabela 8 , incluíram-se apenas variáveis preditivas ligadas ao contexto de investimentos em startups envolvendo as seguintes categorias: tipo de indústria e número de mercados atendidos, número de colaboradores, rodadas de financiamento (tempo e valores) e local de origem.

A modelagem e interpretação de modelos de machine learning requer técnica e domínio do contexto de negócios envolvido no problema de classificação ou regressão. Pelo background dos autores desta pesquisa, este estudo contribui ao aproximar o campo da Ciência de Dados ao da Administração. Esperamos, com isso, fomentar pesquisas conjuntas para avançar o conhecimento acadêmico.

Do ponto de vista dos investidores, que geralmente investem em mais de uma startup e montam um portfólio delas, uma precisão de
$26,4 \%$ equivale a uma taxa de acerto de 1 para 3,8 startups na carteira. Pelo design desta pesquisa, a Classe 0 , considerada como fracasso, é constituída por startups que continuam em operação e recebendo funding, muito longe de serem caracterizadas como uma opção de investimento a ser descartada.

Assim, o uso de modelos de machine learning para classificação binária tem sua aplicabilidade para os investidores, principalmente na fase de mapeamento de startups promissoras, com taxa de acerto de 1 para cada 3,8 startups identificadas pelo classificador. Tal precisão é valiosa em um cenário extremamente competitivo, onde mais de $90 \%$ das startups falham e menos de $1 \%$ se tornam unicórnios, ou seja, startups com valor de mercado (valuation) acima de um bilhão de dólares (Profitfromtech, 2020).

O mecanismo de classificação proposto neste estudo pode agregar um filtro inicial (uma espécie de screening - varredura) de opções, para que os investidores possam alocar mais tempo em análises posteriores envolvendo a parte financeira, operacional e mercadológica, buscando um aprofundamento analítico na busca de targets com maior probabilidade de sucesso.

As mudanças realizadas no design de pesquisa proposto por Arroyo et al. (2019) abrem frentes para pesquisadores avançarem, tanto no processo de tratamento dos dados faltantes usando a estratégia conservadora deste estudo, quanto na criação de novos atributos pertinentes ao ecossistema empreendedor. 
Outras contribuições são a estratégia para lidar com a natureza desbalanceada das classes, os testes com outros modelos, e novas opções para escolha dos melhores hiperparâmetros.

\section{Referências}

Arroyo, J., Corea, F., Jimenez-Diaz, G., \& Recio-Garcia, J. A. (2019). Assessment of machine learning performance for decision support in venture capital investments. IEEE Access, 7, 124233-124243. https://doi.org/10.1109/ACCESS.2019.2938 659

Basole, R. C., Park, H., \& Chao, R. O. (2019). Visual Analysis of Venture Similarity in Entrepreneurial Ecosystems. IEEE Transactions on Engineering Management, 66(4), 568-582.

https://doi.org/10.1109/TEM.2018.2855435

Bento, F. R. S. R. (2017). Predicting Start-up Success with Machine Learning. Master Program in Information Management. Instituto Superior de Estatística e Gestão da Informação. Universidade Nova de Lisboa. Recuperado de: https://run.unl.pt/bitstream/10362/33785/1/T GI0132.pdf. Acesso em 14/mai/2020.

Blank, S. (2013). The Four Steps to the Epiphany: successful strategies for products that win. Pescadero: K\&S Ranch Press.

CB Insights. (2020). The Complete List of Unicorn Companies. Recuperado de: https://www.cbinsights.com/researchunicorn-companies. Acesso em 10/dez/2020.

Cremades, A. (2016). The Art of Startup Fundraising: pitching investors, negotiating the deal, and everything else entrepreneurs need to know. Hoboken: John Wiley \& Sons.

Crunchbase. Crunchbase Platform. Disponível em: https://www.Crunchbase.com/. Acesso em: 12 mar. 2020.
Dalle, J.-M., Den Besten, M. \& Menon, C. (2017). Using Crunchbase for economic and managerial research. OECD Science, Technology and Industry Working Papers. Recuperado de: https://pdfs.semanticscholar.org/aa83/4b1dd d1d6c96bde1c6e526be6bb2a99ad011.pdf. Acesso em 07/jun/2020.

Ertel, W. (2017). Introduction to Artificial Intelligence. $2^{\text {nd }}$ ed. London: Springer.

Facelli, K., Lorena, A. C., Gama, J., \& de Carvalho, A. C, P. L. F. (2019). Inteligência Artificial: uma abordagem de aprendizado de máquina. Rio de Janeiro: LTC.

Gastaud, C., Carniel, T., \& Dalle, J.-M. (2019). The varying importance of extrinsic factors in the success of startup fundraising: competition at early-stage and networks at growth-stage. arXiv preprint arXiv: 1906.03210. Recuperado de: https://arxiv.org/abs/1906.03210. Acesso em 03/jun/2020.

Gereto, M. A. S. (2019). Caracterização dos ciclos de investimentos de venture capital em startups brasileiras em termos de rodadas de investimento e estratégias de desinvestimento a partir de dados da Crunchbase. Dissertação de mestrado em administração. FGV - Faculdade Getúlio Vargas, 2019. Recuperado de; http://bibliotecadigital.fgv.br/dspace;/handle /10438/27468. Acesso em 01/jun/2020.

Hsieh, K.-H., \& Li, E. Y. (2017). Progress of Fintech industry from venture capital point of view. In: Proceedings of The 17th International Conference on Electronic Business. ICEB, Dubai, p. 297-301. Recuperado de: http://iceb.johogo.com/proceedings/2017/IC EB_2017_paper_36-WIP.pdf. Acesso em 3/jun/2020.

Kemeny, T., Nathan, M., \& Almeer, B. (2017). Using Crunchbase to explore innovative ecosystems in the US and UK. Birmingham Business School Discussion Paper Series. Recuperado de: http://epapers.bham.ac.uk/3051/1/bbs-dp- 
2017-01-nathan.pdf. Acesso em $01 / \mathrm{abr} / 2020$.

Kosterich, A., \& Weber, M. S. (2018). Starting up the News: The Impact of Venture Capital on the Digital News Media Ecosystem.

International Journal on Media

Management, 20(4), 239-262.

https://doi.org/10.1080/14241277.2018.1563 547

Kubat, M. (2017). An Introduction to Machine Learning. $2^{\text {nd }}$ ed. Suiça: Springler.

Liang, E., \& Daphne Yuan, S.-T. (2013). Investors Are Social Animals: Predicting Investor Behavior using Social Network Features via Supervised Learning Approach. In: Proceedings of the Workshop on Mining and Learning with Graphs (MLG-2013), Chicago. Recuperado de: http://chbrown.github.io/kdd-2013usb/workshops/MLG/doc/liang-mlg13.pdf. Acesso em 03/jun/2020.

Losada, B. (2020). Finanças para Startups: o essencial para empreender, liderar e investir em startups. São Paulo: Editora Saint Paul.

National. Small Business Failure Rate. Recuperado de: https://www.national.biz/2019-smallbusiness-failure-rate-startup-statisticsindustry/. Acesso em 06/abr/2020.

Nylund, P. A., \& Cohen, B. (2017). Collision density: driving growth in urban entrepreneurial ecosystems. International Entrepreneurship and Management Journal, 13(3), 757-776. https://doi.org/10.1007/s11365-016-0424-5

Pan, C., Gao, Y., \& Luo, Y. (2018). Machine Learning Prediction of Companies 'Business Success. CS229: Machine Learning, Stanford University. Recuperado de: http://cs229.stanford.edu/proj2018/report/88 .pdf. Acesso em 25/mar/2020.

Porter, M. E. (2005). Estratégia Competitiva. Rio de Janeiro: Campus.
Profitfromtech (2020). The Ultimate List of Startup Statistics for 2020. Recuperado de: https://www.profitfromtech.com/startupstatistics/. Acesso em 01/out/2020.

Ries, E. (2012). A Startup Enxuta. $1^{a}$ ed. São Paulo: Leya.

Shan, Z., Cao, H., \& Lin, Q. (2014). Capital Crunch: Predicting Investments in Tech Companies. CS221 Project: Crunchbase Investment Prediction. Training, 5831(32462), 32462. Recuperado de: http://www.zifeishan.org/files/capitalcrunch.pdf. Acesso em 12/jun/2020.

Skiena, S. S. (2017). The Data Science Design Manual. Suiça: Springer. 